\title{
Anti-GNRH Receptor Monoclonal Antibodies are Long Acting Analogs of GNRH
}

Lee $\mathrm{G}^{*}$

UBC Centre for Reproductive Health, Canada

*Corresponding author: Gregory Lee, UBC Centre for Reproductive Health, c/o 9117 Shaughnessy Street, Vancouver, Canada, V6P 6R9, Tel: 778-322-4651; Email:

\section{Review Article}

Volume 1 Issue 4

Received Date: October 05, 2016

Published Date: November 22, 2016 leecyg@gmail.com

\section{Abstract}

Monoclonal antibodies were generated against a synthetic peptide corresponding to N1-29 sequence located in the extracellular domain of human GnRH (gonadotropin-releasing hormone) receptor. Among the fourteen established monoclonal antibodies GHR103 and GHR106 were shown to have the highest affinity $\left(K_{d} \approx 2 \times 10^{-9}\right.$ M) to the synthetic peptide as well as to the native GnRH receptor in cancer cell extract. Through immunoglobulin gene analysis, both GHR103 and GHR106 were shown to have identical DNA sequences in both heavy and light chains of IgG1 subclass. GHR106 was shown to be highly specific to N1-29 peptides derived from GnRH receptor of human and monkey, but not to that from mouse. Immunohistochemical studies were performed with as many as 30 different cancer cell lines and were found to positively stain more than $80 \%$ of cases, irrespective of their tissue origins. Consistent results were obtained with other assays such as Western Blot, indirect immunofluorescence and RT-PCR. Similar to GnRH decapeptide antagonist, Antide, GHR106 was shown to induce apoptosis and inhibit cell proliferation to culturing cancer cells by TUNEL and MTT assays, respectively. Furthermore, GHR106 was shown to induce lysis of cancer cells in culture through complement-dependent cytotoxicity reactions (CDC) which are absent with GnRH peptide analogs. Humanized forms of GHR106 (hGHR106) were generated and found to be bioequivalent to murine GHR106 (mGHR106) as well as to GnRH antagonist, Antide in terms of their respective binding affinity and biological properties. Widespread expressions of GnRH receptor among various human cancer, hGHR106 can be bioequivalent alternative to GnRH decapeptide analogs and can serve as the antibody-based anti-cancer drugs of much longer half-life as compared to that of GnRH decapeptide analogs (days vs. hrs.). Furthermore, humanized GHR106 can be long-acting substitute to GnRH decapeptide analog for numerous gynecological indications in fertility regulations and women health.

Keywords: GHR106; Anti-GnRH Receptor; Bioequivalent GnRH Analog; Monoclonal Antibodies; Humanized GHR106

\section{Introduction}

GnRH is a decapeptide hormone secreted by hypothalamus and acts on GnRH receptor in the anterior pituitary to stimulate the release of gonadotropin, LH and FSH for differentiation and maturation of reproductive functions in gonadal tissues [1-3]. Due to the relative short half-life of native GnRH, (2-6 min) in circulations [1- 
3], numerous peptide derivatives of GnRH with longer half-life (hrs.) were male available and act similarly to GnRH in biological functions. Due to structural variations, these derivatives were classified into either agonists or antagonists depending on their differential actions to stimulate or inhibit the release of gonadotropins [4-6].

GnRH decapeptide analogs are among the most versatile drugs for treatments of many gynecological indications and women health $[4,5]$. In addition to its direct actions on pituitary and gonadal related tissues or organs, $\mathrm{GnRH}$ receptor is also expressed by almost all cancer cells. The binding of GnRH analogs to GnRH receptor expressed on the surface of most cancer cells could result in induced apoptosis of cancer cells $[4,5,7]$. Therefore, GnRH peptide analogs have been considered suitable anti-cancer drugs for therapeutic treatments of various human cancer, especially breast and ovarian cancer [1, 8].

Recently, monoclonal antibodies against N1-29 in the extracellular domains of GnRH receptor have been generated and demonstrated to be bioequivalent to $\mathrm{GnRH}$ decapeptide analogs in terms of its biological actions, except that the former has a much longer half-life in circulations (5-21 days) when compared to those of decapeptide analogs [9-13]. Moreover, bioactive fragments of monoclonal antibodies can be generated by various manipulations including humanizations, Fab (2.5 $\mathrm{kDa}),(\mathrm{Fab})_{2}(50 \mathrm{kDa})$ and ScFv (10-15 kDa, single chain variable fragments of Fab). Depending on therapeutic applications, these bioactive fragments can be introduced for various treatments in fertility regulations or cancer $[2,14]$. Therefore, we believe that the diversity of these anti-GnRH receptor monoclonal antibodies or their bioactive fragments can be considered as the first-in-class $\mathrm{GnRH}$ analogs for future clinical applications [15]. For cancer treatments, antibody-based GnRH analogs can also be conjugated with various cytotoxic chemicals for more effective cancer treatments $[4,5]$.

Therefore, in this short review, we would like to highlight the biochemical and immunological characterizations of humanized anti-GnRH monoclonal antibodies. The potential applications of these antibodies can be demonstrated through their bioequivalence to GnRH decapeptide analogs as summarized in this review.

\section{Generations of Monoclonal Antibodies against Human GnRH Receptor}

As early as two decades ago, genes of GnRH receptors were identified and sequenced at DNA and protein levels $[1,3,16]$. The amino acid sequences of the peptides located in the extra-cellular domains were fully determined and assigned $[17,18]$. They are located, respectively in N1-29, N182-193, N195-206 and N293-306 of the corresponding
GnRH receptor $[12,19]$. Early attempts were made to generate suitable monoclonal antibodies against the synthetic peptides corresponding to those in the extracellular domains of GnRH receptor. So far, only the monoclonal antibodies against N1-29 synthetic peptides could only be successfully generated $[12,19]$. Among these antibodies, GHR-103 and GHR-106 in our laboratory were shown to have the highest affinity and specificity to human GnRH receptor $\left(\mathrm{k}_{\mathrm{d}}=1-5 \times 10^{-9} \mathrm{M}\right)$. Further DNA sequence analysis of IgG genes of GHR-103 \& GHR-106 revealed that both are identical in DNA/amino acid sequences (Lee G, unpublished observations). Therefore, our extensive studies were focused on GHR106 reported in this reviews [9-13].

\section{Biological and Immunological Characterizations of GHR106}

\section{Biochemical Studies}

GHR106 monoclonal antibody was shown to have high affinity and specificity to human $\mathrm{GnRH}$ receptor $\left(\mathrm{K}_{\mathrm{d}}\right.$ $\approx 1 \times 10^{-9} \mathrm{M}$ ). Both N1-29 synthetic peptide from human GnRH receptor and GnRH receptor dried on OC-3-VGH ovarian cancer cell extract were employed separately for binding assays with typical ELISA and Western Blot assays [9-13]. In addition, as many as 30 different cultured cancer cell lines were employed for immunocytochemical assays with GHR106 as the probe. With almost no exceptions, GHR106 was shown to stain positively to most of these cancer cell lines [9-13]. Similar results were obtained by indirect immune fluorescent assay.

RTPCR was utilized as the tool for detection of gene expression of GnRH receptor. The results of RTPCR were consistent with those of indirect immune fluorescent assay and Western Blot assay [9-13]. Based on biochemical / immunological analysis, it can be established that anti-GnRH receptor, GHR106 exhibits high specificity and affinity to human GnRH receptor $[20,21]$. In view of the high degree homology of N1-29 amino acid sequences of $\mathrm{GnRH}$ receptor between human and monkey (90\%), GHR106 was also found to crossreact with monkey $\mathrm{GnRH}$ receptor as expected, but not with the mouse one $[20,21]$.

\section{Biological and Immunological Studies}

The bioequivalence between GHR106 and GnRH decapeptide analog (Antide) was investigated by several in vitro studies $[10,19]$. Both GnRH antagonist, Antide and GHR106 were shown to induce apoptosis to cultured cancer cells in a dose-dependent manner as demonstrated by TUNEL assay [21,22]. Compared to the negative 
control, GHR106 of mouse origin (mGHR106) and humanized GHR106 (hGHR106) were shown to induce apoptosis to cultured OC-3-VGH cultured cancer cells at concentrations ranging from $2 \mu \mathrm{g} / \mathrm{ml}$ to $10 \mu \mathrm{g} / \mathrm{ml}$. Both mGHR106 and hGHR106 exhibit similar degree of apoptosis to cancer cells at a concentration of $10 \mu \mathrm{g} / \mathrm{ml}$ or lower [9-13]. In the case of decapeptide GnRH analog, Antide, significant but similar apoptosis was induced at a concentration of $0.1 \mu \mathrm{g} / \mathrm{ml}$ [9-13]. The results of this comparative study seemed to indicate that both GHR106 and GnRH decapeptide analog can induce cellular apoptosis of cultured cancer cells to the similar extent, perhaps through similar mechanisms of action $[10,20,21]$. This MTT assays also strongly supports that GHR106 is bioequivalent to $\mathrm{GnRH}$ decapeptide analogs in anti proliferative actions to cancer cells. Therefore, GHR106 can be an ideal alternative candidate of anti-cancer drugs for therapeutic treatments of human cancer, when the relatively long half-life of antibody drugs is taken into considerations. The results of TUNEL assay to illustrate the induced apoptosis upon treatments with either of GHR106 or GnRH peptide analog to OC-3-VGH cancer cells are presented in (Figure 1A) $[10,20]$. Similarly, apoptosis was also induced in several other cultured cancer cell lines such as PC-3 (prostate), A549 (lung) and MDA-MB435 (breast). Results of this study are compared with Antide which serves as the positive control and presented in (Figure 1B). In addition to induced apoptosis to cancer cells, complement-dependent cytotoxicity (CDC) to induce cell lysis of cultured cancer cells was also observed for GHR106 in the presence of complement $[10,20,21]$. In contrast, CDC reactions cannot be induced in cancer cells with GnRH decapeptide antagonist, Antide. The results of CDC reactions study are presented in (Figure 2) with several negative control. Both murine GHR106 (mGHR106) and humanized GHR106 (hGH106) were found to induce apoptosis and CDC reactions to a similar extent [10,20,21]. In summary, the bioequivalence between GHR106 and GnRH peptide analog is well established based on results presented in this study.

(A) Effects of GnRH decapeptide antagonist, Antide, and anti-GnRH receptor Mabs, mGHR106 and hGHR106, on induced apoptosis to OC-3-VGH ovarian cancer cells by TUNEL assay after 48 hours' incubation. Data are presented in histograms and listed as followed ( $\mathbf{m}$ ) in the x-axis: $2 \mu \mathrm{g} / \mathrm{mL}, \quad 4 \mu \mathrm{g} / \mathrm{mL}$, and $10 \mu \mathrm{g} / \mathrm{mL}$ mGHR106, $10 \mu \mathrm{g} / \mathrm{mL}$ hGHR106, and $0.1 \mu \mathrm{g} / \mathrm{mL}$ Antide. ( $\square$ ) represents the negative control with either $10 \mu \mathrm{g} / \mathrm{mL}$ normal mouse IgG or $10 \mu \mathrm{g} / \mathrm{mL}$ human IgG for each corresponding set of experiments. * and ${ }^{* *}$ indicate statistical significance of $\mathrm{P}$ $<0.05$ and $\mathrm{P}<0.01$, respectively.

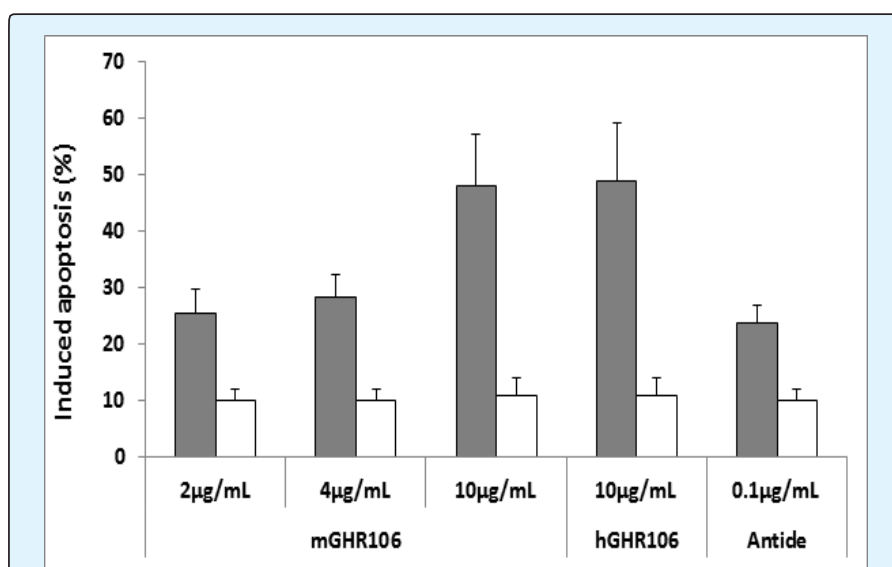

Figure 1(A): Experiments to reveal induced apoptosis and cell lysis by complement-dependent cytotoxicity (CDC) reactions.

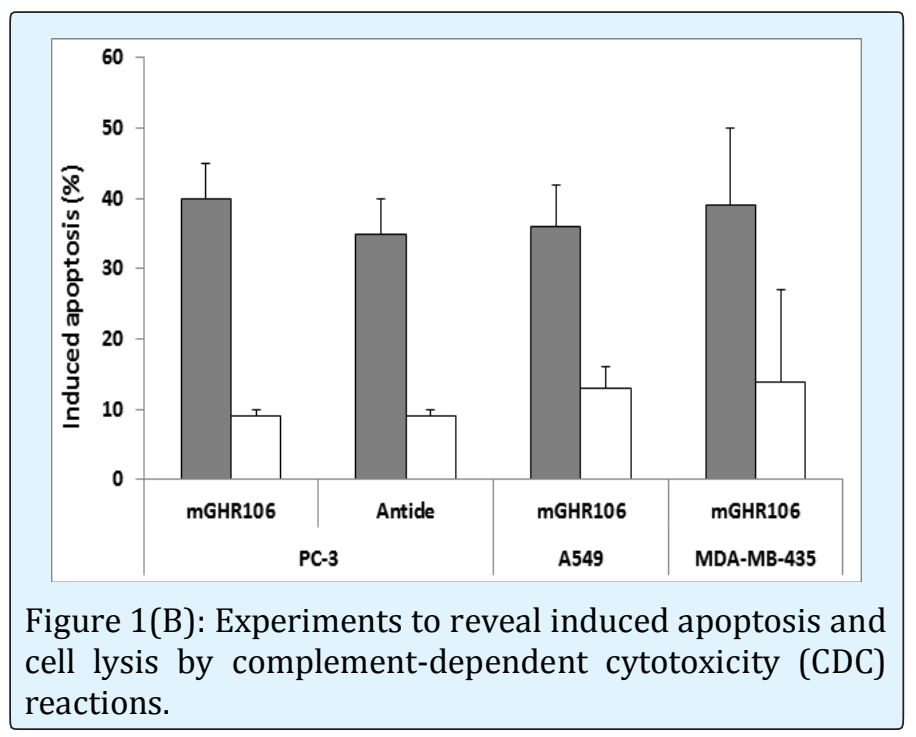

(B) Effects of GnRH decapeptide antagonist, Antide, and anti-GnRH receptor Mab, mGHR106, on induced apoptosis to different cultured cancer cells by TUNEL assay after 48 hours' incubation. Data are presented in histograms and listed as followed ( $\square$ ) in the x-axis: mGHR106 $(10 \mu \mathrm{g} / \mathrm{mL})$ and Antide $(0.1 \mu \mathrm{g} / \mathrm{mL})$ with PC-3 prostate cancer cells; mGHR106 $(10 \mu \mathrm{g} / \mathrm{mL})$ with A549 lung cancer cells; mGHR106 $(10 \mu \mathrm{g} / \mathrm{mL})$ with MDA-MB435 breast cancer cells. ( $\square$ ) represents the negative control with either $10 \mu \mathrm{g} / \mathrm{mL}$ normal mouse IgG or $10 \mu \mathrm{g} / \mathrm{mL}$ human IgG for each corresponding set of experiments. * and ${ }^{* *}$ indicate statistical significance of $\mathrm{P}$ $<0.05$ and $\mathrm{P}<0.01$, respectively. 


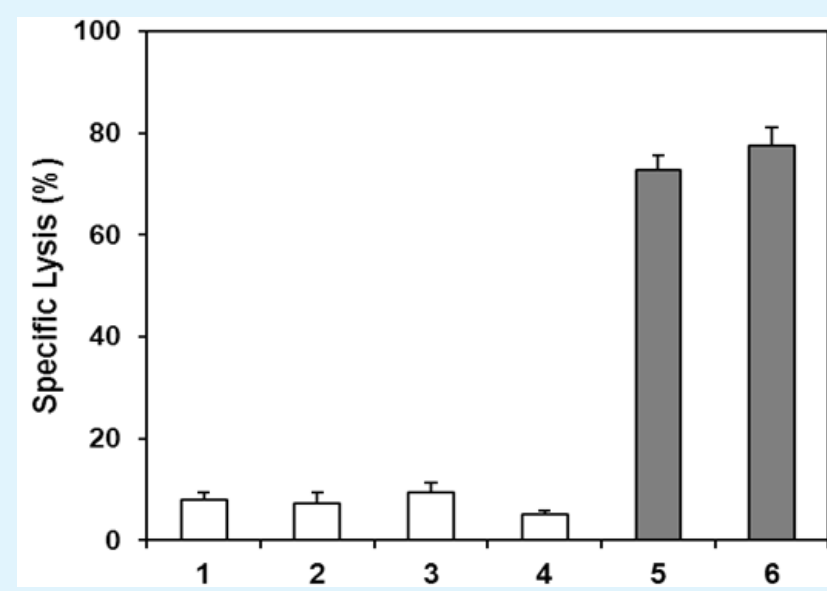

Figure 2: Lanes 1 to 4 represent negative controls. Lane 1: no treatment (negative control); Lane 2: $3 \mu \mathrm{L}$ freshly prepared rabbit baby complement (negative control); Lane 3: normal human IgG $(10 \mu \mathrm{g} / \mathrm{ml}$ plus complement) (negative control); Lane 4: normal mouse IgG $(10 \mu \mathrm{g} / \mathrm{mL}$ plus complement) (negative control); Lane 5: hGHR106 (10 $\mathrm{gg} / \mathrm{ml}$ plus complement) (2-hour incubation); Lane 6: mGHR106 $(10 \mu \mathrm{g} / \mathrm{ml}$ plus complement) (2-hour incubation). ** indicate statistical significance of $\mathrm{P}<0.01$.

\section{Effects of Antibody and Peptide-based GnRH Analogs on Gene Regulations of Cultured Cancer Cells}

Effect of GHR106 and GnRH decapeptide analogs on changes in gene regulations to cultured cancer cells were studied and compared [20]. A number of genes involved in protein synthesis (P0, P1, P2 and P37) and growth/cell cycle regulations (EGF, cfos, P21 and cyclin D) were included for such comparative studies [20]. With no exceptions, both GHR106 and GnRH decapeptide, Antide were found to regulated similarly the gene expression levels of cancer cells upon either ligand treatments $[15,20,21]$. Based on the results of semi-quantitative analysis by RT-PCR, it is interesting to note that Antide and mGHR106 were shown to have identical patterns of gene regulations of the treated culturing cancer cells. For example, upon legend treatments, up regulation of $\mathrm{GnRH}$ gene was observed, whereas GnRH receptor gene is not affected. Down regulation of EGF gene as well as cyclin D1 was observed in the presence of either GnRH analogs. These observations are consistent with the molecular mechanisms of actions of either legend to induce apoptosis of cancer cells [20,21]. However, the information regarding the detailed molecular mechanisms of actions is limited and remains to be elucidated through further investigations in the future $[9,12]$. Nevertheless, the bioequivalence between GHR106 and GnRH decapeptide analog was consistently established $[9,20]$.

Humanization of GHR106 Monoclonal Antibody: In vitro biochemical and immunological studies as described in the above have suggested biological/functional equivalence between GHR106 and decapeptide GnRH analogs. For therapeutic applications in humans, it is essential to structurally modify the murine GHR106 into humanized forms [15]. Briefly, the human frame work and donor selection were made through germline search. $\mathrm{V}_{\mathrm{L}}$ and $\mathrm{V}_{\mathrm{H}}$ sequences were selected through the rearrangement of human IgG data base and the best hits in each group were aligned. Finally, one germline FR donor and one rearranged FR domains were selected by taking into the consideration of CDR length, canonical structure as well as proline residues, which are essential for the proper folding of humanized antibody [15]. Structural modeling and back mutation were performed to those residues that are predicted significantly to affect CDR loop structure. The overall objective of this engineering works in to minimize the immunogenicity and maximize preservation of antigen binding affinity and specificity of the resulting humanized antibodies [23,24]. After four rounds of humanization designs, several humanized GHR106 are generated, expressed and affinity-purified.

All of these humanized isoforms were produced with human IgG, heavy chain as well as light chain kappa constant region. Through biochemical and immunological studies as described in previous section, (Figure 1 and 2), the humanized GHR106 revealed good potency when compared to that of parental mGHR106. Antibody and decapeptide $\mathrm{GnRH}$ analogs showed comparable affinity and specificity to N1-29 synthetic peptide of GnRH receptor as well as its native form in cancer cell extract [12]. Both mGHR106 and hGHR106 can induce apoptosis and complement-dependent cytotoxicity to cultured cancer cells in vitro. In summary, both murine and humanized GnRH analogs were demonstrated to be bioequivalent to GnRH decapeptide analogs based on the reported in vitro biochemical and immunological studies $[12,20,21]$.

Potential Applications of Humanized GHR106 as AntiCancer Drugs: In view of the high specificity and affinity of GHR106 to human, GnRH receptor, humanized GHR106 may be an alternative GnRH analog to the corresponding decapeptide ones [3,16,19]. Both GnRH peptide analogs and GHR106 (mGHR106 and hGHR106) exhibit very similar functional and biological activities to $\mathrm{GnRH}$ receptor expressed on the surface of most cancer cells. However, GHR106 has a much longer circulation half-life 
compared to peptide analogs and are capable of inducing complement-dependent cell lysis through CDC reactions [9-13]. In contrast, such reactions do not exist in the GnRH peptide analogs. The long half-life of GHR106 may have unexpected benefit over the peptide ones for more effective treatments of human cancer [9-13]. Furthermore, bioactive hGHR106 fragments can also be generated through established bio-engineering methods for adoption of versatile clinical applications in the future $[15,19,25,26]$. Based on these considerations, hGHR106 and its smaller bioactive antibody fragments may have potential clinical applications similar to those of decapeptide GnRH analogs not only in cancer, but also many gynecological indications $[10,11,19,26]$.

Similar to GnRH decapeptide analogs, treatment withGHR106 may also affect pituitary functions to inhibit gonadotropin release. However, such side effects may not be critical during the short term cancer treatments.

\section{Strategies of Antibody-Based Cancer Therapy}

Basically, two strategies are currently available for clinical applications of hGHR106 or its bioactive antibody fragments in cancer therapy. One is the passive immunization of hGHR106 in gram or subgram quantity to cancer patients who are undergoing treatment. The other is CAR-T cell therapy. Basically, hGHR106 genes are packaged into a vector in a form of chimeric antigen receptors (CAR) $[27,28]$. Transfections of patients own T cells with CAR-related vector were performed for further expansion of $\mathrm{T}$ cells by in vitro culture. The transfected expanded T cells can result in hGHR106 expression to target cancer cells in vivo upon transfusion of the CARtransfected T cells $[29,30]$.

GHR106-related CAR-T system may represent a promising approach for cancer immunotherapy in the future. The gene for hGHR106 may be assembled in different forms including whole antibodies, bioactive fragments such as Fab, Fab' or $\left(\mathrm{Fab}^{\prime}\right)_{2}$ as well as recombinantly produced single chain antibodies ( $\mathrm{ScFv}$ ), the last of which are commonly used in CAR-T technology $[31,32]$.

Stable CHO cell lines secreting hGHR106 have been developed for large scale productions of hGHR106 and can be used for passive immunization as anticancer drugs. Preclinical studies by using hGHR106 are being carried out to meet the criteria of IND (initial new drug) development, as required by US FDA [15]. Therefore, preclinical and clinical studies of hGHR106 are warranted for successful development of the antibody-based anticancer drugs with multiple indications $[13,17]$.

\section{Discussion and Conclusions}

In this mini-review, the generation and characterizations of a monoclonal antibody against human GnRH receptor, GHR106 were highlighted $[9,10]$. The unique properties of this antibody specific to the extracellular domain of this receptor were demonstrated to be bioequivalent to GnRH and its decapeptide analogs $[20,21]$. Due to difference in peptide sequence homology, GHR106 was shown to be highly specific to human and monkey receptor, but not to mouse [20, 21]. Both GHR106 and GnRH analogs exhibit almost identical biological but not immunological properties $[9,20]$ including induced cellular apoptosis and binding specificity to many cancer cells $[12,21,26]$. However, GHR106 can induce complement-dependent cytotoxicity (CDC) to cancer cell and exhibits a much longer half-life (days vs. min/hrs) as compare to $\mathrm{GnRH}$ peptide analogs. Following humanization processes, humanized GHR106 (hGHR106) is virtually identical to murine GHR106 (mGHR106) in all biological and immunological properties to cancer cells [9-13]. Therefore, with the newly advanced CAR-T (Chimeric Antigen Receptor T cell Therapy) technology, the incorporations of hGHR106 gene into CAR-T format has been successfully carried out and validated for further preclinical and clinical studies [29, 30]. HGHR106 can also been produced in large scale for immunotherapeutic applications of many types of human cancer $[15,31,32]$. Therefore, it can be concluded that hGHR106 can serve as the long-acting alternatives of GnRH peptide analogs which are being utilized for cancer treatments or for numerous indications in fertility regulation $[13,17]$.

\section{References}

1. Hazum E, Conn PM (1988) The Molecular Mechanism of GnRH Action. I. The GnRH Receptor. Endocr Rev 9(4): 379-386.

2. Clayton RN (1989) Gonadotropin-Releasing Hormone: Its Action and Receptors. J Encrinol 120: 11-19.

3. Flanagan CA, Millar RP, Illing N (1998) Advances in Understanding Gonadotrophin Releasing Hormone Receptor Structure and Ligand Interactions. Rev Reprod 2(2): 113-120.

4. Montagnani MM, Moretti RM, Mai S, JanuszkiewiczCaulier J, Motta M, et al. (2009) Type l GonadotropinReleasing Hormone Receptor Mediates the Antiproliferative Effects of GnRH-II on Prostate Cancer Cells. J Clin Endocrinol Metab 94(5): 17611767. 
5. Nagy A, Schally AV (2005) Targeting of Cytotoxic Luteinizing Hormone-Releasing Hormone Analogs to Breast, Ovarian, Endometrial, and Prostate Cancers. Biol Reprod 73(5): 851-859.

6. Weckermann D, Harzmann R (2004) Hormone Therapy in Prostate Cancer: LHRH Antagonists versus LHRH Analogues. Eur Urol 46(3): 279-284.

7. So WK, Cheng JC, Poon SL, Leung PC (2008) Gonadotropin-Releasing Hormone and Ovarian Cancer: a Functional and Mechanistic Overview. FEBS J 275(22): 5496-5511.

8. Kang SK, Choi KC, Yang HS, Leung PCK (2003) Potential Role of Gonadotrophin-Releasing Hormone (Gnrh)-1 and Gnrh-11 in the Ovary and Ovarian Cancer. Endocr Relat Cancer 10: 169-177.

9. Lee G, Cheung AP, Ge B, Zhu M, Giolma B, et al. (2012) CA215 and GnRH Receptor As Targets for Cancer Therapy. Cancer Immunol Immunother 61(10): 18051817.

10. Lee G, Ge B (2010) Growth Inhibition of Tumor Cells In Vitro By Using Monoclonal Antibodies against Gonadotropin-Releasing Hormone Receptor. Cancer Immunol mmunother 59(7): 1011-1019.

11. Lee G, Ge B (2012) Implications of Apoptosis in Cancer Immunotherapy. Adv Biosci Biotechnol 3: 679-685.

12. Lee G, Ho J, Chow SN, Yasojima K, Schwab C, McGeer PL (2000) Immunoi dentification of Gonadotropin Releasing Hormone Receptor in Human Sperm, Pituitary and Cancer Cells. Am J Reprod Immunol 44(3): 170-177.

13. Lee G, Zhu MG, Ge B (2012b) Potential Monoclonal Antibody Therapy for the Treatmentof Ovarian Cancer. In: Farghaly SA (eds.) Ovarian cancer - basic science perspective. In Tech, Vancouver, pp. 385-406.

14. Choi JH, Gilks CB, Auersperg N, Leung PCK (2006) Immunolocalization of Gonadotropin-Releasing Hormone Gnrh-I, Gnrh-II, and Type I Gnrh Receptor During FollicularDevelopment in the Human Ovary. J Clin Endocrinol Metab 91(11): 4562-4570.

15. Lee G, Huang CY, Ge B (2014) Two Distinct Humanized Monoclonal Antibodies for Immunotherapy of Ovarian Cancer. J Cancer Sci Therapy 6: 110-116.
16. Kakar SS, Musgrove LC, Devor DC, Jeffrey CS, Jimmy DN (1992) Cloning, Sequencing and Expressionof Human Gonadotropin Releasing Hormone (GnRH) Receptor. Biochem Biophys Res Commun 189(1): 289-295.

17. Montagnani MM, Moretti RM, Januszkiewicz-Caulier J, Motta M, Limonta P (2006) Gonadotropin-releasing hormone $(\mathrm{GnRH})$ receptors in tumors: a new rationale for the therapeutical application of GnRH analogs in cancer patients? Curr Cancer Drug Targets 6(3): 257269.

18. Limonta P, Montagnani MM, Mai S, Motta M, Martini L, et al. (2012) GnRH Receptors in Cancer: From Cell Biology to Novel Targeted Therapeutic Strategies. Endocr Rev 33(5): 784-811.

19. Karande AA, Rajeshwari K, Schol DJ, Hilgers JH (1995) Establishment of Immunological Probes to Study Human Gonadotropin-Releasing Hormone Receptors. Mol Cell Endocrinol 114(1-2): 51-56.

20. Lee G, Zhang H, Tang Y (2013) Anti-GnRH Receptor Monoclonal Antibodies as Bioequivalent Analogs of GnRH. In: Sills ES (eds,) Gonadotropin-Releasing Hormone (GnRH): Production, Structure and Function. Nova Biomedical, Los Angeles, pp. 157-174.

21. Lee G, Chow SN, Chien CH, Liu S (2015) Anti-GnRH Receptor Monoclonal Antibodies, First-in-Class GnRH Analog. J Gynecol Res 1(1): 102.

22. Filman DJ, Brawn RJ, Dandliker WB (1975) Intracellular supravital stain delocalization as an assay for antibody-dependent complement-mediated cell damage. J Immunol Methods 6(3): 189-207.

23. Wu TT, Kabat EA (1970) An analysis of the sequences of the variable regions of Bence Jones proteins and myeloma light chains and their implications for antibody complementarity. JExpMed 132(2): 211-250.

24. Chothia C, Lesk AM, Tramontano A, Levitt M, SmithGill SJ, et al. (1989) Conformation of Immunoglobulin Hypervariable Regions, Nauture 342(6252): 877-883.

25. Vazquez J, Gonzalez L, Merino, Vizoso F (2000) Expression and Clinical Significance of Apolipoprotein D in Epithelial Ovarian Carcinomas. Gynecol Oncol 76(3): 340-347. 
26. Gadadhar S, Karande AA (2013) Abrin Immunotoxin: Targeted Cytotoxicity and Intracellular Trafficking Pathway. PloS ONE 8(3): e58304.

27. David E, Reno D, Martin P, Robert E, Hawkins, et al. (2012) CAR-T cells and solid tumors: tuning T cells to challenge an inveterate foe. Trends in Molecular Medicine 18(7): 377-384.

28. Ritchie DS, Neeson PJ, Khot A, Peinert S, Tai T, et al. (2013) Persistence and efficacy of second generation CAR T cell against the LeY antigen in acute myeloid leukemia. Mol Ther 22(11): 2122-2129.

29. Lamers CH, Sleijfer S, van Steenbergen S, van Elzakker P, van Krimpen B, et al. (2013) Treatment of Metastatic Renal Cell Carcinoma with Caix CAREngineered $\mathrm{T}$ Cells: Clinical Evaluation and Management of on-Target Toxicity. Mol Ther 21(4): 904-912.
30. Bai M, Trivedi S, Brown E (1998) Dimerization of the extracellular calcium-sensing receptor (CaR) on the cell surface of CaR-transfected HEK293 cells. J Biol Chem 273(36): 23605-23610.

31. Davila ML, Riviere I, Wang X, Bartido S, Park J, et al. (2014) Efficacy and Toxicity Management of 19-28z CAR T Cell Therapy in B Cell Acute Lymphoblastic Leukemia. Sci Transl Med 6(224): 224ra25.

32. Cheadle EJ, Gornall H, Baldan V, Hanson V, Hawkins RE, et al. (2014) CAR T Cells: Driving the Road from the Laboratory to the Clinic. Immunol Rev 257(1): 91106. 